DEPARTMENT OF ECONOMICS, MANAGEMENT AND STATISTICS

UNIVERSITY OF MILAN - BICOCCA

DEMS WORKING PAPER SERIES

\title{
A Two-Party System under the Proportional Rule is Possible: Strategic Voting in the Lab
}

Francesco De Sinopoli, Giovanna Iannantuoni,

Valeria Maggian, Stefania Ottone

No. 381 - May 2018

Dipartimento di Economia, Metodi Quantitativi e Strategie di Impresa

Università degli Studi di Milano - Bicocca

http://dems.unimib.it/ 


\title{
A Two-Party System under the Proportional Rule is Possible: Strategic Voting in the Lab
}

Francesco De Sinopoli (University of Verona), Giovanna Iannantuoni (University of MilanoBicocca), Valeria Maggian (University of $\mathrm{Ca}^{\prime}$ Foscari), Stefania Ottone (University of MilanoBicocca)

\begin{abstract}
In this study, we implement a series of voting games in the laboratory to test whether a strategic voting behavior in a proportional system would arise and induce a two-party system. In each voting game, a finite number of subjects with single-peaked preferences, uniformly distributed on a $0-20$ line, are asked to vote for a number within the interval 0-20. The policy outcome is the average of the chosen numbers - a realistic representation of a compromise between parties in a parliament elected through the proportional rule. Our main result shows that polarization and strategic voting occur in the proposed proportional rule scenario. Moreover, experience and information concerning the electoral outcome of the previous period drive individuals to opt for strategic voting.
\end{abstract}

Keywords: Proportional representation; strategic voting; polarization; political compromise; laboratory experiment; information.

JEL Classification: C91, C92, D72. 


\section{Introduction}

The implemented electoral system in a country sets the Parliament. The performance of a Parliament may be measured through a series of criteria. However, there is a general agreement on the fact that two criteria are the most relevant-governability and representativeness. ${ }^{1}$ The former represents "the capacity to effectively govern the State," while the latter refers to "the capacity to correctly represent the choices of the electors." ${ }^{2}$ The number of parties in the Parliament negatively affects governability but positively influences representativeness. In line with this argument, if proportional systems favor multipartyism (Duverger, 1954), then they can turn out to be more representative than plurality systems. However, this result would be connected to the fact that strategic voting is absent under proportional representation and, consequently, everyone votes for their favorite party. ${ }^{3}$ Contrary to Duverger's (1954) hypothesis, more recent empirical (Abramson et al. 2010; Kedar, 2005) and theoretical (Bargsted and Kedar, 2009; Cox and Soberg, 1996; Hobolt and Karp, 2010) contributions have proven that tactical voting is not limited to a plurality contest. Moreover, the existence of two-party-equilibria when a proportional rule is implemented has been proven theoretically by recent studies (De Sinopoli and Iannantuoni, 2007; Gerber and OrtuñoOrtìn, 1998), in the presence of incomplete information (Troumponis and Xefeteris, 2015). Austria and Ireland represent real-life cases of a reduced number of parties under proportional representation.

This study aims to test experimentally whether a strategic voting behavior in a proportional system would arise and induce a two-party system. Our study contributes to the stream of literature investigating how the electoral laws condition the strategic behavior of parties, candidates, and voters. An increasing number of studies have experimentally investigated the emergence of strategic voting in multiparty systems under proportional representation. Blais et al. (2014) analyzed strategic voting when parties are organized in pre-electoral coalitions, and a minimum electoral threshold is required for a party to obtain seats - when the history of play is made available, the players are less likely to vote sincerely than when the information about previous elections is not provided. Similarly, Meffert and Gschwend (2011) investigated the role of voters' expectations about future coalitions on voters' strategic behavior. The authors manipulated the availability of polls and coalition signals by parties in different treatments and found that, among others, voters

\footnotetext{
${ }^{1}$ For a detailed discussion on this point and a list of related references, refer to Ortona, 2000.

${ }^{2}$ Ortona et al., 2008, p. 23.

${ }^{3}$ Strategic voting is defined as the decision of voters to support a different candidate more strongly when compared to their preferred candidate to get a more desirable outcome. Voters may decide to misrepresent their preferences instead of voting sincerely, depending on the election's voting rules.
} 
seem to rely on several heuristics instead of voting strategically, depending on the complexity of the decision task. As shown by van der Strateten et al. (2010), it is not essential for computations in experiments to be too demanding to observe strategic voting. Kamm and Schram (2013) analyzed the interactions between voter's turnout decision and party choice in a proportional system with five voters and three parties. Through a framed experiment, they showed that the voter turnout is linked to (exogenous) party polarization, when in the presence of coalitions. In their experiment, they allowed for voting to be voluntary, meaning that people may eventually decide to abstain (i.e., voting is costly). Analyzing a different set of electoral rules, Dellis (2013) provided experimental evidence that plurality and approval voting, wherein each voter can cast a vote for one candidate and any number of candidates, respectively, lead to a two-party system, while negative voting, wherein each voter can vote for all candidates, except one, does not lead to a two-party system. We contribute to this stream of literature by implementing a lab experiment to examine whether voters have the ability and willingness to vote strategically, when provided with different levels of information and experience, in a very simple proportional setting. This setting does not involve predefined parties, coalitions, costly voting, and political framing, and it operates on a very simple electoral rule.

Our main result shows that polarization and strategic voting occur in our proportional rule scenario. Moreover, experience and information concerning the electoral outcome of the previous period drive people to vote strategically. Starting with this simple framework, in future research, it would be easier to identify those characteristics that enhance rather than discourage strategic voting in proportional rule settings.

Section 2 deals with the experimental design and procedures. Section 3 describes our experimental hypotheses (based on the model by De Sinopoli and Iannantuoni, 2007). Section 4 is devoted to the data analysis. Section 5 provides a robustness check of our main results with respect to the policy outcome rule. Section 6 concludes the study.

\section{Experimental design and procedures}

\subsection{Experimental design}

In our experiment, we focus on voting behavior by examining the following two main dimensions: i) the policy outcome and ii) the role played by information concerning the distribution of the electoral pool. The experimental design consists of the following two treatments: the Info Average Treatment (AverageInfo) and the No-Info Average Treatment (AverageNoInfo). In each treatment, the experimental task consists of a series of voting games where subjects are allocated on a 0-20 
axis and are asked to choose a number between 0 and 20. This means that, in each voting game, each subject has the opportunity to vote for a party that perfectly represents the subject's best policy.

In the AverageInfo treatment, participants' positions are randomly allocated from a discrete uniform distribution without replacement. This implies that each participant receives a number between 0 and 20 and it is not possible for two subjects to have the same number. Contrarily, in the AverageNoInfo treatment, participants' positions are randomly allocated from a discrete uniform distribution with replacement. In this case, subjects are not provided with any precise information concerning the distribution of the electoral pool, but they know that it is possible for two or more subjects to have the same assigned number.

In each voting game, the voting procedure leads to an electoral outcome that is determined as the average of all chosen numbers. As explained in De Sinopoli and Iannantuoni (2007), this simple rule captures the spirit of the proportional representation system, wherein all parties represented in parliament contribute to its legislative activity. Evidently, the higher the number of votes, the higher will be the possibility to influence the governmental outcome. ${ }^{4}$

Each participant's payoff is inversely correlated with the distance between the participant's own position and the electoral outcome of the voting game. ${ }^{5}$ To be precise, it is equal to:

$$
\pi_{j}=20-\mid \text { electoral outcome - subject's location } \mid
$$

In each treatment, subjects are asked to participate in the following five phases - a no_feedback phase (NF), three feedback_fixed_role phases (FFR), and a feedback_changing_role phase (FCR) comprising five rounds each. The phases are played sequentially, and participants receive instructions about each of them only after the completion of the preceding phase.

At the beginning of each round of the NF phase, each subject is assigned a position and is asked to play the voting game for five rounds. During this phase, although no feedback is provided concerning the electoral outcome, beliefs about it are elicited. Particularly, after each voting decision, subjects are asked to guess the outcome of the preceding period, excluding their voting decision. ${ }^{6}$ In this phase, we investigate whether i) individuals act rationally with respect to their

\footnotetext{
${ }^{4}$ This outcome is also interesting because it represents the utilitarian solution of a bargaining process among politicians with a quadratic loss function (Refer to Baron and Diermeier, 2001).

${ }^{5}$ Subjects' preferences are single-peaked.

${ }^{6}$ Particularly, participants are asked to state their (not incentivized) beliefs in each round of the first phase of the game, immediately after their voting decision. Participants are not informed about the beliefs elicitation task when their voting
} 
beliefs about others' choices, ii) play strategically and independently on their positions on the 0-20 line, and iii) whether the beliefs of individuals reflect their observed behavior. Since each participants' location changes randomly at each round and no feedback is given about the electoral outcome, our approach allows for a precise analysis of how one's position affects the decision to vote strategically.

Contrarily, in each of the FFR phases, each participant's assigned number remains constant throughout the five rounds and feedback about the electoral outcome is provided after each round. A comparison of participants' behavior between the NF and the FFR phases enables us to consider the learning effects in driving strategic behavior. While the positions shift from one election to the next in the NF phase, in the FFR phases, decisions are made by participants located in the same position. Therefore, in the FFR condition, individuals have an opportunity to experience the effect of their choices on the electoral outcome, and eventually update their behavior and beliefs.

Finally, similar to the first phase, in the FCR phase, a number is randomly allocated to each participant at the beginning of each round. However, as in the FFR phases, feedback about the electoral outcome is given to all the participants after each round. In this phase, we investigate whether individuals' behavior observed in the FFR phase reflects a learning process. For example, do we observe an increasing percentage of strategic choices in the FFR phase due to learning or due to a sequence of successful trials (since each participant's assigned number remains fixed for five rounds)? In the FCR, since participants' positions shift from one round to the other, strategic voting necessitates an immediate response, so that a lower percentage of strategic choices will indicate that the learning process was not completely effective. Overall, each subject plays 25 voting games.

\subsection{Experimental procedures}

The experiment was programmed using the zTree (Fischbacher, 2007). We conducted eight sessions (four per treatment) at the experimental laboratory of the University of Milano-Bicocca (Experimental Economics Lab (EELAB)). In all treatments, participants were recruited via the Online Recruitment System for Economic Experiments (ORSEE) software (Greiner, 2004). Totally, 168 subjects participated in the experiment ( 84 people per treatment). We adopted a betweensubjects design — each subject participates in one treatment only. Instructions were written to induce a neutral environment. ${ }^{7}$ There was no mention of voting or parties. The labels were kept abstract to

decision is taken. If they are not sure about their beliefs, they are also given an opportunity to flag an "I'm not sure" option.

${ }^{7}$ For the English version of the instructions (originally in Italian), please refer the Appendix. 
avoid any confounding in our results such as the role of intrinsic motivation in determining the decision to vote. ${ }^{8}$ Participants were informed that the experiment was composed of several phases, but they received instructions on each phase only after the completion of the preceding phase.

At the end of the experiment, after getting responses to a few demographic questions, one period of each phase was randomly selected for payment. Subsequently, all payoffs were summed up and converted into Euros. The duration of each experimental session was about 45 minutes, and the average payment was 13 Euros.

\section{Experimental hypotheses}

Our experimental hypotheses are based on the model by De Sinopoli and Iannantuoni (2007). The experimental framework is such that: i) the policy space is a closed interval on the real line without any restriction on the number of electable political parties, ii) the position of the government is a linear combination of the parties' policies weighted based on the corresponding share of votes, iii) a finite number of voters participate in the election game, and iv) the unique restriction on voters' preferences is single-peakedness.

Hypothesis 1. Both in the AverageInfo and AverageNoInfo treatments, voters positioned at 10 will vote for their own position, while participants on the former's right and the left will vote for 20 and 0 , respectively.

Proposition 1 is a fairly intuitive result since it represents the Nash Equilibrium, both in the AverageInfo and AverageNoInfo treatments: people whose position is different from 0, 10, and 20 decide to strategically misrepresent their preferences and choose to vote for extremist parties to obtain an outcome much closer to their preferred policy. Nonetheless, it may be the case that voters are not able to immediatly and correctly infer the structure of the game and that participants may in fact play actions different than the ones predicted for a fully rational player.

In the second hypothesis, we expect feedback about the outcome of previous voting games to affect participants" choices, concerning a no-feedback environment. Recent experiments on voting and elections (Bhattacharya et al., 2014; Drouvelis et al., 2014) show that the repetition of the game has a positive effect on the probability that individuals would converge toward the equilibrium.

\footnotetext{
${ }^{8}$ In a recent experiment by Baghdasaryan et al. (2017), framing voting as an election rather than in neutral terms has been shown to have an impact on voters' behavior. In order to avoid any confounding effects on our results, we decided to use abstract labels and terms in our study.
} 
Hypothesis 2. The repetition of the voting game drives the choices of individuals toward strategic voting and the Nash equilibrium, wherein a participant positioned at 10 will vote for own position, while participants on the former's right and the left will vote for 20 and 0 , respectively.

\section{Results}

We report results from 8 experimental sessions (four sessions for each of the AverageInfo and AverageNoInfo treatments), with 21 subjects playing 5 parts (each composed of 5 rounds) in each session.

Our sample is balanced in terms of age composition and the field of study; all the participants were students from the University of Milano-Bicocca, of which $86.3 \%$ were undergraduate Economics students; their average age is 21.6 years. Concerning gender, $42.9 \%$ female participated in the AverageNoInfo treatment (a slightly lower proportion when compared to the AverageInfo treatment, where $53.6 \%$ participants were female). In both treatments, there was a conspicuous group of students who attended a game theory course $(38 \%)$, although there were less number of participants in the AverageNoInfo treatment (29.8\% vs. $46.4 \%$ in the AverageInfo Treatment). ${ }^{9}$ Finally, concerning the participants who took a class in game theory, females and males were almost equally represented (30.56\% females and 29.17\% males in the AverageNoInfo treatment and $44.21 \%$ females and $48.51 \%$ males in the AverageInfo treatment).

The analysis of our experimental data consists of three main points. First, in a context where the policy outcome is a weighted compromise between the different parties, and voters' preferences are single-peaked and allocated in a unidimensional policy space, our aim is to check whether: i) people are more likely to vote strategically than sincerely and ii) the information concerning the distribution of the assigned numbers plays a role. Second, we investigate the role of experience in affecting our experimental subjects' choices. Particularly, our aim is to investigate whether people: i) learn how to vote strategically and ii) react to the information concerning the history of the voting games played in the previous rounds. Finally, we make a comparison between the electoral outcome across treatments.

\footnotetext{
${ }^{9}$ In our data analysis, we control for any of these conditions to affect our results.
} 


\subsection{AverageInfo and AverageNoInfo Treatments}

The first step of our analysis involved analyzing participants' choices under the AverageInfo and AverageNoInfo Treatments. Figure 1 splits the policy space into two parts, including the positions between 1 and 9 and between 11 and 19, respectively, and describes the distribution of votes over the 25 rounds. Since the information provided to subjects concerning other people's location should not be relevant to the determination of their optimal strategy, we expect voters' behaviors to remain unchanged when comparing the AverageInfo and the AverageNoInfo treatments. Therefore, in the following section, we focus mainly on the AverageInfotreatment and provide additional comparisons with respect to the AverageNoInfo treatment.

In Figure 1, we observed a polarization of choices in both treatments - people on the left of the policy space were more inclined to choose numbers lower than 10, with a high preference for zero, while the opposite was observed on the right side of the policy space.

\section{FIGURE 1 HERE}

In the following section, we identify the proportion of sincere and strategic voting. We define voting as "strict sincere voting" ( $S S i V)$ when participant $i$ 's vote is equal to own randomly assigned number, while we define voting as "strict strategic voting" (SStV) if participant $i$ 's choice equals to 0 (20) when the participant's assigned number is lower (higher) than 10. Since it is impossible to identify the voting type of participants whose assigned number is equal to 0,10 , or 20 , strategic and sincere choices would coincide, we label their choices as "non-defined," and we exclude them from our analysis. ${ }^{10}$ Overall, in the AverageInfoTreatment, we can classify more than $53 \%$ of the choices $-44.4 \%$ as strategic and $8.9 \%$ as sincere. Moreover, strategic choices are more popular than sincere ones (paired t-test ${ }^{11}$, $, \mathrm{H} 0: \mathrm{SStV}=\mathrm{SSiV}, \mathrm{t}=8.7728, \mathrm{p}=0.000$; Shlag's Z-test, $\mathrm{z}=23.94$, $\mathrm{p}=0.000)^{13}$

If we would analyze participants' choices at an individual level, then we would find that half of the participants choose to vote strategically more than $45 \%$ of the times. When focusing on the persistence of sincere voting, we find that the median value of the number of times a subject

\footnotetext{
${ }^{10}$ This implies that we dropped 297 observations from our sample.

${ }^{11}$ In order to partially satisfy the requirement of the independence of the observations, for each participant, we measured the ratio of strict strategic choices and the ratio of strict sincere choices with respect to the number of rounds where their position was different from 0,10 , and 20. A paired t-test was performed on these variables.

12 The non-parametric Wilcoxon test provides the same result.

${ }^{13}$ Recently, it has been shown that Mann-Whitney tests and commonly used non-parametric tests are not necessarily providing correct results. Therefore, we provided results from both Shlag's Z test and more common tests. For further information about it, refer to Schlag (2015).
} 
chooses to vote sincerely is $4 \%$. Moreover, $35 \%$ of the subjects never opt to vote for their assigned number. Results remain almost unchanged when comparing the proportion of strategic and sincere voting in the AverageInfo and AverageNoInfo treatments, as shown in Table 2. The results of both the t-test and the Schlag's $Z$ test show that the null hypothesis of equal proportion of strategic behavior between treatments cannot be rejected at the standard levels of significance.

RESULT 1. The proportion of strategic choices is significantly higher than sincere voting both in the AverageInfo and AverageNoInfo treatments.

Concerning the AverageInfo treatment, a detailed analysis of the choices of individuals shows that strategic voting is more popular among subjects whose assigned number does not lie in the center of the policy space. In Figure 2, we observe that a U-shape describes the percentage of strategic voting per assigned number. If we classify individuals according to their position, as in van der Straeten et al. $(2010)^{14}$, we will find that the centrists are less likely to vote strategically than the moderates and extremists $(23.48 \%, 44.32 \%$, and $58.42 \%$ respectively).

\section{FIGURE 2 HERE}

Concerning the AverageNoInfo treatment, the percentage of strategic choices with respect to the voter's assigned number is similar to those observed when full information about others' location is provided $-62.26 \%, 42.22 \%$, and $24.32 \%$ of the choices are defined as strict strategic voting when considering extremist, moderate, and centrist voters, respectively.

RESULT 2. The proportion of strategic voting is higher for moderates and extremists than for the centrists.

The support for Result 2 is provided in Table 1 where we regress voters' types, according to their position on the 0-20 line, on strategic voting (random effects probit regression). Extremist and moderate are two binary variables that equal to one if the voter's position belongs to the aforementioned categorization, zero otherwise. In the analysis, we also include voters' age and

\footnotetext{
${ }^{14}$ We identify voters as extremists (positions from 1 to 3 and from 17 to 19), moderates (positions from 4 to 7 and from 13 to 16 ), and centrists (positions $8,9,11$, and 12)
} 
other binary variables to control for the participants' gender (the variable female is equal to one for females, zero for males) and the field of study (economics is equal to one if the participant is studying economics, zero otherwise). Finally, the variable game theory controls for whether the participant has already taken a class in game theory. We observe that, with respect to those in the center of the policy space, the more the voters are positioned in the extremes, the higher will be the probability that they will vote for 0 or 20 . Moreover, participants who have already studied game theory are more likely to vote strategically, as shown by the (even slightly) significant coefficient of the variable game_theory. Surprisingly, females seem less likely to vote strategically than males. We will provide further hypotheses on this in Section 4.3.

\section{TABLE 2 HERE}

In order to investigate whether such behavior is determined by people in the center having different beliefs about others' voting behavior, in the following section, we analyze participants' beliefs in the first part of the experiment wherein the feedback was absent and participants were reallocated to a new position in every round.

In Figure 3.a, we plot the beliefs of individuals about the average number resulting from others' votes with respect to their assigned number. Therefore, as it can be noted, the probability to guess that the voting outcome differs from 10 does not seem to be dependent on the assigned number. In Figure 3.b and 3.c, we plot individuals' guesses regarding their chosen number when being located, respectively, in a position lower or higher than 10 . When expecting the average to be 10 , people should vote for the extreme party that is closer to their own position. As it can be easily seen in Figure 3.b and 3.c, a substantial proportion of individuals continued to vote for the center (or, even more surprisingly, for the opposite extreme) in such a situation. A more detailed analysis and examination of the behavior across periods shows that the results would remain unchanged. This implies that the less strategic behavior of individuals closer to the center cannot be explained by different beliefs about the election's outcome without the vote of these individuals.

An alternative explanation may be attributed to the bias of individuals toward voting for the expected outcome of the elections; in such a situation, the expected monetary loss for not voting strategically would be lower for those located in the center than for those in the extremes; it ensures that the former may still prefer to vote according to their biases. 
In the previous discussion, we defined strategic voting in a very strict way; this definition enabled us to categorize more than $50 \%$ of the choices in both the treatments. However, in our analysis, it is our aim to allow the voters to make small errors in their judgments or to try different alternatives before correctly understanding the optimal behavior in the game. In this context, in the following analysis, we investigated whether it is possible to classify a higher proportion of choices by relaxing the definition of strategic and sincere voting. Particularly, we defined voting as "weak sincere voting" (WSiV) when the participant $i$ 's vote was set within a range of $+/-1$ with respect to the participant's randomly assigned number, while we defined voting as "weak strategic voting" (WStV) when the participant $i$ 's choice was equal to either 0 or 1 (either 19 or 20) when her assigned number was lower (higher) than 10. By applying the same reasoning as before, when the participant's assigned number is equal to 1 (19), her strategic vote would correspond to 0 (20). Again, we excluded participants from our analysis whose assigned number was equal to 0, 10, or 20.

By allowing for a more flexible definition of voting types, we observed that the proportion of choices that we can classify increased up to $63 \%$ and $62 \%$ in AverageInfo and AverageNoInfo treatments, respectively. There was an increase in both strategic voting and sincere voting, and our main result remained unchanged-strategic voting is significantly more common than sincere voting (paired t-test ${ }^{15}$ and Shlag's Z-test performed; refer to Table 2 for details)).

Finally, irrespective of the kind of analysis, no difference in voting behavior is observed when comparing the AverageInfo and AverageNoInfo treatments (see Table 2 for a summary). This suggests that the role of information on others' locations does not necessarily affect voters' strategic behavior, as shown in Result 3.

RESULT 3. Strategic and sincere voting behavior do not depend on whether participants have full information about others' location on the 0-20 line.

\footnotetext{
${ }^{15}$ Additionally, in this case, for each participant, we measured the ratio of weak strategic choices and the ratio of weak sincere choices with respect to the number of rounds wherein their position was different from 0,10 , and 20 . The paired $\mathrm{t}$-test is performed on these variables.
} 


\subsection{Learning and final outcome}

Having studied the convergence of the subjects' choices toward the equilibrium in the AverageInfo and AverageNoInfo treatments, we examine in which phases and periods this convergence takes place.

In order to understand whether participants learn how to play strategically during the experiment, in this section, we analyze their voting behavior along the five phases of each treatment. In the first phase, participants do not receive any feedback about their voting behavior, and hence it becomes impossible for them to learn about the game. Moreover, their assigned number typically differs from one period to the other, so that their chosen number should be dependent on their position. Contrarily, in the subsequent second, third, and fourth phases of the experiment, each participant receives feedback about the electoral outcome in each round; each participant's location remains constant throughout the five rounds of each phase. This ensures that participants have the opportunity to experience the outcome of their choices for a longer time. As a result, we should observe an increasing convergence toward the equilibrium both within and across phases. Finally, in the last phase of the experiment, while participants continue to receive feedback about the electoral outcome, they change their location in every round of the game-if learning effectively increases the probability of participants playing strategically, then we would observe that this will be independent of their assigned number. To investigate this, in Figure 4, we report the percentage of strategic voting across phases. We also split these phases into periods. In looking for evidence of learning, we compare observations in the first phase with those in the other phases. Moreover, we compare the strategic behavior in the first two and the last two rounds of each phase.

\section{FIGURE 4 HERE}

Our data on voting behavior in the AverageInfo (AI in Figure 4) and AverageNoInfo (AN in Figure 4) treatments indicate a movement toward equilibrium as subjects gain experience.

In the AverageInfo treatment, the differences in the likelihood of voting strategically between the first and the last two periods are largely significant only when considering the second and third phases of the experiment - when feedback about the electoral outcome is given to participants, and their location on the 0-20 line is fixed (paired t-test for FFR1 and FFR2 phases, respectively$\mathrm{p}=0.005, \mathrm{p}=0.018$ ). The effect of feedback on strategic voting is stronger, when we consider the AverageNoInfo treatment; on an average, when comparing the first two and last two periods, respectively, $29.87 \%$ and $50.65 \%$ of the votes are defined as strategic in the FFR1 phase (paired t- 
test: $\mathrm{p}=0.000$ ), and similar outcomes are obtained when considering the FFR2 and FFR3 phases ( 38.66 vs. $60.27 ; 46.48$ vs. 57.75 , respectively; paired t-test: $p=0.000, p=0.058$ ). Contrarily, in the first phase of the game, there is no evidence of an increasing strategic voting across periods (paired t-test for the AverageInfo and AverageNoInfo treatments, respectively: $p=0.330, p=0.791$ ); on an average, only almost $25 \%$ and $26.82 \%$ of the choices are categorized as strictly strategic.

Our results suggest that equilibration becomes faster when feedback is provided to participants. Interestingly, when the participants change their location on the 0-20 line, it becomes apparent that experience does not necessarily increase the capability of participants to play strategically. In the AverageNoInfo treatment, when comparing the last period of the FFR1 phase with the first period of the FFR2 phase, we observe a significant decrease in the observed frequency of strategic behavior (paired t-test: $\mathrm{p}=0.029$ ), and the same is observed when comparing the first and last periods of FF2 and FF3 phases (paired t-test: p=0.029), respectively. However, such a "restart effect" is not significant when considering the AverageInfo treatment; this implies that the information about others' location is important in determining the process of learning how to play strategically.

What happens when the assigned number of individuals changes in each period? When analyzing the frequency of strategic choices in the FCR phase, we find that participants are not more likely to play strategically, even after playing 15 periods of the game with feedback. Further evidence shows that a one-sided paired t-test reaches (weak) significance when testing for the hypothesis that strategic voting is higher in the FF3 phase than in the FCR phase, both when considering the AverageInfo and AverageNoInfo treatments ( $\mathrm{p}=0.068$ and $\mathrm{p}=0.083$, respectively).

Our main result, reported in the following statement, suggests an adaptive behavior of the experimental subjects throughout the repetition of the game.

RESULT 4. Both in the AverageInfo and AvergeNoInfo treatments, subjects learn how to play strategically along the rounds. Information about others' location and feedback about the electoral outcome are important for determining the process of learning how to play strategically.

In the second step, in table 3, we report the marginal effects of a random effect probit model where we investigate the probability to vote strategically, by depending on the experimental phase and on the period. In the model (1), we consider the following independent variables: the binary variable Average_info takes the value one when participants are uniformly distributed on the 0-20 line and full information about it is provided; contrarily, it takes the value zero when the opposite is true. 
No feedback is equal to one if the participant is playing the first phase, while it is equal to zero otherwise. Similarly, the binary variable Feedback_changing is equal to one when considering the last phase of the game and zero otherwise. Therefore, the omitted group is composed of the three central phases wherein feedback about the electoral outcome is provided and participants' location is fixed. Finally, we include the binary variables female, economics, and game_theory to control for the participants' gender, field of study, and whether they have already taken a class in game theory. The categorical variable age considers the age of the participant. In the model (2), besides considering the same variables of control of the model (1), we include only those phases in the analysis wherein feedback is provided to participants; the omitted group is the feedback phase wherein participants change their position in every round to ensure that the independent binary variables are feedback_fixed1, feedback_fixed2, and feedback_fixed3, respectively, for the second, third, and fourth phases of the game. We also investigate the effect of the experience within the same phase by interacting the phase of the game with the period in the interaction terms feedback_fixed $1 * P$, feedback_fixed $2^{*} P$, and feedback_fixed $3 * P$. When including the interaction terms in the regression, the value of the main terms feedbackfixed1, feedback fixed2, and feedback_fixed 3 represent the difference in the intercepts between the feedback phases with fixed participants' location and with changing locations when the period has a value of zero. However, the period cannot have a zero value so that we will shift the zero point to the mean of period. Finally, in models (3) and (4), we run the same regression as in the model (2), but separately for each treatment.

\section{TABLE 3 HERE}

Results in Table 3 confirm our previous analysis. Particularly, in the model (1), we observe that feedback plays a fundamental role in increasing the proportion of strategic voting. The variable Feedback_changing fails to reach significance, implying that when participants' location is fixed to a situation where their assigned number differs from one period to another, there is no difference in terms of the probability to vote strategically. Contrarily, the variable No_feedback is highly significant, and hence receiving feedback about the electoral outcome increases the likelihood of strategic voting.

In the model (2), we provide further evidence that experience positively affects the probability to vote strategically; the negative and significant coefficient of Feedback_fixed1 reveals that strategic 
voting is more likely to occur in the last phase rather than in the first phase with feedback, when considering a mean value for the period. However, as shown by the significant positive coefficient of Feedbackfixed3, for the mean level of the period, participants are more likely to vote strategically in the last phase wherein they receive feedback and locations are fixed than when locations are changing. This effect is driven by observations in the AverageNoinfo treatment, as shown by the significant value of Feedback fixed 3 in the model (4), but not in the model (3). This implies that, when information about others' location is not provided, the observed increase in strategic voting does not reflect the true learning process, but rather reflects the ability of participants to find an optimal strategy in a specific situation. The coefficient of the period is positive and significant; it implies that, in the last phase of the experiment, there is an increasing probability to vote strategically, even at a lower degree when compared to the previous phases, as periods proceed.

Finally, in both the models, the probability to vote strategically significantly increases if the participant is male or if the participant has studied game theory, as shown by the significance of the variables female and game theory. While the fact that taking a class on game theory makes it easier for participants to reason strategically is somehow an intuitive result, the gender effect on strategic voting is less immediate to understand. Robust differences between men and women in risk preferences, social (other-regarding) preferences, and competitive preference have been already identified (Croson and Gneezy, 2009; Niederele, 2016). If voting strategically, i.e. not truthfully revealing their own political preferences, is considered as lying, then strategic behavior will be lower in women than men, in accordance with the recent literature on gender differences in honesty (for a meta-analysis see Capraro, 2017).

If we focus on the voting outcome, we would observe that it is located at a small interval containing 10 in the last round of each part of both treatments. More importantly, we observe that while approaching the last period of every phase, the electoral outcome seems to converge to 10 . This evidence confirms our previous analysis as per which, in both the treatments, experience makes participants more likely to vote strategically, and such behavior will result in a policy outcome that is a compromise between the extreme bipartisan partition of the policy space. In Figure 5, we plot the average electoral outcome in each period of each experimental phase.

\section{FIGURE 5 HERE}




\section{Role played by the final policy computation and the median treatment}

What is the effect of the final policy computation on the emergence of strategic behavior? According to De Sinopoli and Iannantuoni (2007), the procedure that leads to the policy outcome plays a fundamental role. When the final outcome comprises a linear combination of parties' positions weighted with the share of votes that each party receives (as we did in AverageInfo and AverageNoInfo Treatments), "the incentive to vote for an extreme is given by the maximal effect that such a vote has on the outcome. Vice versa, if the policy outcome is the median, voting sincerely is a dominant strategy because the effect of each vote, but the median one, is solely 'directional' (i.e., any vote to the left of the median has the same effect as well as any vote to the right)" (De Sinopoli and Iannantuoni, 2007, p.268, footnote 2).

We study this issue by running an additional treatment with 84 participants. With respect to the AverageInfo treatment, in the median Treatment, everything remains the same with the exception that the electoral outcome is determined as the median of all players' choices. Participants in this study were, as in the previous one, undergraduate students of the University of Milano Bicocca; additionally, $78.6 \%$ were undergraduate Economics students, their average age was 21.8 years, and $47.6 \%$ were female. Around $30 \%$ of them took courses in game theory.

In this treatment, it is common knowledge that voters are uniformly allocated on the $0-20$ line; unlike in the AverageInfo treatment, it is not possible for two voters to hold the same number. Since there are 21 participants in total, the median is the number that equally divides voters into two fractions of the same size once their choices are sorted in ascending order. Therefore, in such an environment, strategic voting would have a different definition when compared to the definition in the preceding paragraphs. In this case, sincere voting and strategic voting coincide because it is not possible for a participant to move the median closer to own position by voting a lower number than the assigned one when expecting others to apply the same reasoning.

\section{Hypothesis 3. Each participant will vote for own position.}

Hypothesis 3 immediately derives from the Nash equilibrium of the game: sincere voting is the dominant strategy. Figure 6 describes the distribution of votes (overall 25 rounds) according to the assigned position on the policy space. It immediately stands out that, even if 0,10 , and 20 are more popular than other choices, people's choices are more spread over the policy space.

\section{FIGURE 6 HERE}


Subjects who participated in the median treatment voted sincerely more often than in the average treatments. Particularly, considering the strict definition that we used in the average treatments analysis, in 352 out of 1800 cases (19.6\%), we observe sincere voting. This value is significantly higher when compared to the average treatments ( $\mathrm{t}$-test ${ }^{16}, \mathrm{t}=4.852, \mathrm{p}=0.000$; Shlag's Z-test, $\mathrm{z}=11.6115, \mathrm{p}=0.000)$.

In Figure 7, we plot the proportion of sincere choice with respect to the participant's assigned number. As in the average treatments, the position on the political space plays a role in determining the probability to vote optimally. Particularly, while the voting behavior resembles a U-shape in the average treatments, we observe that the opposite is true for the median treatment - centrists are more likely to vote optimally, that is, sincerely, than those participants whose assigned number is closer to the extremes.

\section{FIGURE 7 HERE}

In the previous section, we showed how experience plays a role in subjects' learning process in the average treatments. Receiving feedback about the electoral outcome seems to be a fundamental tool to increase participants' likelihood to vote strategically. However, we observe that the frequency of optimal choices does not increase across phases or across periods in the median treatment; the percentage of cases in which subjects adopt the weakly dominant strategy (strict sincere voting) reaches the minimum level during the second FFR (17\%) and does not overcome the 23\% (in the FCR). In Figure 8, we report the percentage of strategic voting across phases and we split these phases into periods.

\section{FIGURE 8 HERE}

Therefore, the size of the learning critically depends on the treatment. While the learning effect across phases is substantial in both the AverageInfo and AverageNoInfo treatments, there is significantly no such evidence in the median treatment.

\footnotetext{
${ }^{16}$ As before, the t-test was performed to measure the ratio of strict sincere choices with respect to the number of rounds wherein their position was different from 0,10 , and 20.
} 
RESULT 5. In the median treatment, participants are significantly more likely to vote sincerely than in the average treatments. The frequency of optimal voting does not increase with experience.

However, the observed "restart effect" across phases that we have observed in the AverageNoInfo treatment may reflect another component of how feedback might influence the increasing strategic voting of participants; it is possible that people do not learn how to play optimally but rather react to the history of the voting games. By holding a constant position on the 0-20 line, participants get the opportunity to see the result of their choices immediately in order to adjust their choices across periods. When asked to take the same decision in another position, it might be essential for them to experience the same process again to play optimally.

Such a reasoning is particularly interesting when considering the median treatment; participants' optimal strategy is to play sincerely. However, we do observe a low proportion of optimal choices. In the median treatment, we define player $i$ 's choice as path dependent when it is lower/higher than the policy outcome of the previous period, and the assigned number is lower/higher than the policy outcome. Clearly, the optimal choice should be to vote sincerely, but even in this case we cannot exclude that subject $i$ is reacting to what happened in the previous period.

We observe that the addition of the "path dependent" category to the strict sincere one facilitates the classification of more than $70 \%$ of the choices in the median treatment. Particularly, in the FFR 1 phase, $19.44 \%$ of the choices are strict sincere and $48.96 \%$ of the choices are defined as pathdependent, while these frequencies equal to $15.97 \%$ and $47.92 \%$ in the FFR2 phase and to $17.36 \%$ and $61.11 \%$ in the FFR3 phase.

Concerning the electoral outcome, in Figure 9, we observe that it is much less stable in the median treatment than in the average treatments; while approaching the last period of every phase, the electoral outcome does not converge to 10 but goes in all directions.

\section{FIGURE 9 HERE}

\section{Conclusion}

In this study, we ask experimental subjects to participate in a series of voting games (with or without feedback concerning the history of the policy outcomes during the experiment) in the lab to test whether a strategic voting behavior in a proportional system may arise and induce a two-party system. Our setting does not involve pre-defined parties, coalitions, costly voting, and political 
framing. A total of 21 participants positioned on the line $0-20$, with single-peaked preferences, has to vote for a number between 0 and 20. The policy outcome is the average of the voted numbers. Depending on the treatment, information about the distribution of the electoral pool is (not) provided to subjects. Our main result is that polarization and strategic voting occur in our proportional rule scenario. Moreover, experience and information concerning the electoral outcome of the previous period drive people to strategic voting.

In order to check to what extent the policy outcome rule influences subjects' strategic choices, we implement a treatment where the policy outcome is the median of the voted numbers, and we find that sincere voting - the dominant strategy — is the most popular choice.

The main policy implication is that, in a real scenario, where the policy outcome is compromised between different political trends, strategic voting may be widespread and polarization possible. Our study is relevant for two main reasons. First, it shows that people can vote strategically even in a proportional representation scenario wherein sincere voting is easier but does not constitute the dominant strategy. Further research is needed to investigate the role of pre-election coalitions, the possibility of abstaining, and strong political ideologies; these issues are relevant for determining the voting behavior.

\section{References}

Abramson, P.R., Aldrich, J.H., Blais, A, Diamond, M., Diskin, A., Indridason, I.H., Lee, D.J., and Levine, R. 2010. Comparing Strategic Voting under FPTP and PR. Comparative Political Studies, 43(1): 61-90.

Baghdasaryan, V., Iannantuoni, G., and Maggian, V. 2017. Electoral fraud and voter turnout: an experimental study. GATE - Lyon Saint-Etienne, WP 1716.

Bargsted, M.A., and Kedar, O. 2009. Coalition-Targeted Duvergerian Voting: How Expectations Affect Voter Choice under Proportional Representation. American Journal of Political Science, 53(2): 307-23.

Baron, D.P., and Diermeier, D. 2001. Elections, governments, and parliaments in proportional representation systems. Quarterly Journal of Economics, 116:933-967

Bassi, A. 2015. Voting Systems and Strategic Manipulation: an Experimental Study. Journal of Theoretical Politics, 27(1): 58-85 
Bhattacharya, S., Duffy, J. and Kim, S.T. 2014. Compulsory versus voluntary voting: An experimental study. Games and Economic behavior, 84: 111-131.

Blais, A., Erisen, C., and Rheault, L. 2014. Strategic Voting and Coordination Problems in Proportional Systems: An Experimental Study. Political Research Quarterly, 67(2): 386-397.

Blais, A., Laslier, J.F., Laurentc, A., Saugerd, N., and Van der Straeten, K. 2007. One-round vs Two-round Elections: An Experimental Study. French Politics, 5: 278-286.

Capraro, V. 2017. Who lies? A meta-analysis of the effect of sex, age, and education on honesty. Working paper.

Cox, G.W. and Soberg, M.S.1996. Strategic Voting under Proportional Representation. Journal of Law, Economics, \& Organization, 12(2): 299-324.

Croson, R., and Gneezy, U. 2009. Gender differences in preferences. Journal of Economic Literature, 47(2): 448-74.

De Sinopoli, F., and Iannantuoni, G. 2007. A spatial voting model where proportional rule leads to two-party equilibria. International Journal of Game Theory, 35: 267-286.

Dellis, A. 2013. The two-party system under alternative voting procedures. Social Choice and Welfare, 40: 263-284.

Drouvelis, M., Saporiti, A. and Vriend, N.J. Political motivations and electoral competition: Equilibrium analysis and experimental evidence. Games and Economic behavior, 84: 86-115.

Duverger, M. 1954. Political Parties Their Organization and Activity in the Modern State. New York: Wiley.Fischbacher, U. 2007. z-Tree: Zurich toolbox for ready-made economic experiments. Experimental Economics, 10(2): 171-178.

Gerber, A., and Ortuño-Ortìn, I. 1998. Political compromise and endogenous formation of coalitions. Social Choice and Welfare, 15: 445-454.

Hobolt, S.B., and Karp, J.A. 2010. Voters and Coalition Governments. Electoral Studies, 29 (3): 299-307.

Kamm, A., and Schram, A. 2013. A Simultaneous Analysis of Turnout and Voting under Proportional Representation: Theory and Experiments. Mimeo. 
Kedar, O. 2005. When moderate voters prefer extreme parties: policy balancing in parliamentary elections. American Political Science Review, 99(2): 185-199.

Meffert, M., and Gschwend, T. 2011. Strategic Voting, Proportional Representation, and Coalition Governments: A Laboratory Experiment Issue. European Journal of Political Research, 50(5): $636-667$.

Niederle, M. 2016. Gender in Kagel, J., and Roth, A.E., eds., Handbook of Experimental Economics, second edition, Princeton University Press.

Ortona, G., 2000, A weighted-voting electoral system that performs quite well, in: Dardanoni, V., and Sobbrio, G., eds., Istituzioni politiche e finanza pubblica, Franco Angeli, Milano.

Ortona G., Ottone S., Ponzano F., 'A simulative assessment of the Italian electoral system' in 'Italian Institutional Reforms: A Public Choice Perspective', 2008, edito da F. Padovano - R. Ricciuti, Springer.

Schlag, K.H. 2015. Who gives Direction to Statistical Testing? Best Practice meets Mathematically Correct Tests. Vienna Economics Papers 1512, University of Vienna, Department of Economics.

Troumponis, O., and Xefeteris, D. 2015. Incomplete Information, Proportional Representation and Strategic Voting. Working paper.

Van der Straeten, K., Laslier, JF., Sauger, N., and Blais, A. 2010. Strategic, sincere, and heuristic voting under four election rules: an experimental study. Social Choice and Welfare, 35: 435-472. 


\section{TABLES AND FIGURES}

Table 1. Random effects probit regression on strategic voting - AverageInfo and AverageNoInfo Treatments.

\begin{tabular}{|c|c|c|}
\hline \multirow{2}{*}{$\begin{array}{l}\text { Dependent } \\
\text { variable }\end{array}$} & \multicolumn{2}{|c|}{ Strategic voting } \\
\hline & AverageInfo & AverageNoInfo \\
\hline \multirow[t]{2}{*}{ Extremist } & $1.397 * * *$ & $1.480 * * *$ \\
\hline & $(.113)$ & $(.112)$ \\
\hline \multirow[t]{2}{*}{ Moderate } & $.844 * * *$ & $.837 * * *$ \\
\hline & $(.108)$ & $(.099)$ \\
\hline \multirow[t]{2}{*}{ Female } & $-.511 *$ & $-.576^{*}$ \\
\hline & $(.248)$ & $(.249)$ \\
\hline \multirow[t]{2}{*}{ Age } & -.046 & -.004 \\
\hline & $(.063)$ & $(.070)$ \\
\hline \multirow[t]{2}{*}{ Economics } & .363 & .136 \\
\hline & $(.342)$ & $(.415)$ \\
\hline \multirow[t]{2}{*}{ Game theory } & $.544^{*}$ & $.544^{*}$ \\
\hline & $(.246)$ & $(.274)$ \\
\hline \multirow[t]{2}{*}{ Constant } & -.378 & -1.018 \\
\hline & $(1.458)$ & $(1.651)$ \\
\hline $\mathbf{N}$ & 1782 & 1831 \\
\hline Subjects & 84 & 84 \\
\hline Periods & $1-25$ & $1-25$ \\
\hline Log likelihood & -869.709 & -911.23 \\
\hline Wald chi2 & $160.07 * * *$ & $179.26 * * *$ \\
\hline \multicolumn{3}{|c|}{ Note. $* * *, * *, * *$ denote significance at $1 \%, 5 \%$ and } \\
\hline \multicolumn{3}{|c|}{ Standard deviation on parentheses } \\
\hline
\end{tabular}


Table 2. Distribution of strict voting and weak voting types - AverageInfo and AverageNoInfo

\begin{tabular}{|c|c|c|c|}
\hline \multirow{3}{*}{$\begin{array}{c}\text { Strict } \\
\text { Strategic } \\
\text { Voting (SStV) }\end{array}$} & $\begin{array}{l}\text { AverageInfo } \\
\qquad(\mathrm{N}=\mathbf{1 7 8 2})\end{array}$ & $\begin{array}{l}\text { AverageNoInfo } \\
\qquad(\mathrm{N}=\mathbf{1 8 3 1})\end{array}$ & Ho: AverageInfo $=$ AverageNoInfo \\
\hline & \multirow[b]{2}{*}{$44.4 \%$} & \multirow{2}{*}{$44 \%$} & $\begin{array}{l}\mathrm{t}=-0.1404^{a} \\
\mathrm{p}=0.8885^{a}\end{array}$ \\
\hline & & & $\begin{array}{l}\mathrm{Z}=0.2561^{b} \\
\mathrm{p}=0.7978^{b}\end{array}$ \\
\hline \multirow{2}{*}{$\begin{array}{l}\text { Strict Sincere } \\
\text { Voting (SSiV) }\end{array}$} & \multirow{2}{*}{$8.9 \%$} & \multirow{2}{*}{$8.2 \%$} & $\begin{array}{l}\mathrm{t}=0.3672^{a} \\
\mathrm{p}=0.7139^{a}\end{array}$ \\
\hline & & & $\begin{array}{l}Z=0.7250^{b} \\
p=0.4684^{b}\end{array}$ \\
\hline \multirow{2}{*}{$H 0: S t V=S s i V$} & $\begin{array}{l}\mathrm{t}=8.7728^{a} \\
\mathrm{p}=0.000^{a}\end{array}$ & $\begin{array}{l}\mathrm{t}=9.5787^{a} \\
\mathrm{p}=0.000^{a}\end{array}$ & \\
\hline & $\begin{array}{c}\mathrm{Z}=23.9426^{b} \\
\mathrm{p}=0.000^{b}\end{array}$ & $\begin{array}{c}\mathrm{Z}=24.6062^{b} \\
\mathrm{p}=0.000^{b}\end{array}$ & \\
\hline \multirow{2}{*}{$\begin{array}{l}\text { Weak Strategic } \\
\text { Voting (WStV) }\end{array}$} & \multirow{2}{*}{$48.9 \%$} & \multirow{2}{*}{$49.5 \%$} & $\begin{array}{l}\mathrm{t}=-0.3015^{a} \\
\mathrm{p}=0.7634^{a}\end{array}$ \\
\hline & & & $\begin{array}{l}\mathrm{Z}=0.3619^{b} \\
\mathrm{p}=0.7175^{b}\end{array}$ \\
\hline \multirow{2}{*}{$\begin{array}{l}\text { Weak Sincere } \\
\text { Voting (WSiV) }\end{array}$} & \multirow{2}{*}{$14.2 \%$} & \multirow{2}{*}{$15.3 \%$} & $\begin{array}{l}\mathrm{t}=-0.4681^{a} \\
\mathrm{p}=0.6403^{a}\end{array}$ \\
\hline & & & $\begin{array}{l}\mathrm{Z}=0.8794^{b} \\
\mathrm{p}=0.3792^{b}\end{array}$ \\
\hline \multirow{2}{*}{$\begin{array}{c}\text { Ho: } \\
\text { WSt } V=W S i V\end{array}$} & $\begin{array}{l}\mathrm{t}=7.9234^{a} \\
\mathrm{p}=0.000^{a}\end{array}$ & $\begin{array}{l}\mathrm{t}=7.9833^{a} \\
\mathrm{p}=0.000^{a}\end{array}$ & \\
\hline & $\begin{array}{c}\mathrm{Z}=22.2675^{b} \\
\mathrm{p}=0.000^{b}\end{array}$ & $\begin{array}{c}\mathrm{Z}=22.1367^{b} \\
\mathrm{p}=0.000^{b}\end{array}$ & \\
\hline
\end{tabular}

Note: a: Paired t-test, tests performed on the ratio values; b: Schlag's Z test, tests performed on the proportions. 
Table 3. Random effects probit regression on strategic voting - the role of experience.

\begin{tabular}{|c|c|c|c|c|}
\hline Model & (1) & (2) & (3) & (4) \\
\hline Dependent variable & \multicolumn{4}{|c|}{ Strategic voting } \\
\hline \multicolumn{5}{|l|}{ Independent variable } \\
\hline Average_Info & $\begin{array}{l}-.005 \\
(.057)\end{array}$ & $\begin{array}{l}-.023 \\
(.068)\end{array}$ & - & - \\
\hline No feedback & $\begin{array}{c}-.866^{* * *} \\
(.068)\end{array}$ & - & - & - \\
\hline Feedback_changing & $\begin{array}{c}.005 \\
(.063)\end{array}$ & - & - & - \\
\hline Feedback_fixed1 & - & $\begin{array}{c}-.294 * * * \\
(.081)\end{array}$ & $\begin{array}{c}-.312 * * \\
(.117)\end{array}$ & $\begin{array}{l}-.269 * \\
(.113)\end{array}$ \\
\hline Feedback_fixed2 & - & $\begin{array}{l}-.085 \\
(.082)\end{array}$ & $\begin{array}{c}.050 \\
(.117)\end{array}$ & $\begin{array}{c}.123 \\
(.116)\end{array}$ \\
\hline Feedback_fixed3 & - & $\begin{array}{l}.200 * \\
(.083)\end{array}$ & $\begin{array}{c}.132 \\
(.119)\end{array}$ & $\begin{array}{l}.265^{*} \\
(.116)\end{array}$ \\
\hline Feedback_fixed $1 * P$ & - & $\begin{array}{l}.157 * \\
(.057)\end{array}$ & $\begin{array}{l}.145^{*} \\
(.81)\end{array}$ & $\begin{array}{l}.169^{*} \\
(.079)\end{array}$ \\
\hline Feedback_fixed $2 * P$ & - & $\begin{array}{l}.164 * * \\
(.157)\end{array}$ & $\begin{array}{c}.119 \\
(.081)\end{array}$ & $\begin{array}{l}.209^{*} \\
(.081)\end{array}$ \\
\hline Feedback_fixed $3 * P$ & - & $\begin{array}{l}-.068 \\
(.058)\end{array}$ & $\begin{array}{c}.062 \\
(.084)\end{array}$ & $\begin{array}{c}.071 \\
(.080)\end{array}$ \\
\hline Period & - & $\begin{array}{l}.085^{*} \\
(.040)\end{array}$ & $\begin{array}{c}.085 \\
(.564)\end{array}$ & $\begin{array}{c}.084 \\
(.056)\end{array}$ \\
\hline Female & $\begin{array}{c}-.524 * * \\
(.169)\end{array}$ & $\begin{array}{c}-.654 * * \\
(.199)\end{array}$ & $\begin{array}{l}-.682 * \\
(.288)\end{array}$ & $\begin{array}{l}-.655^{*} \\
(.282)\end{array}$ \\
\hline Age & $\begin{array}{l}-.037 \\
(.044)\end{array}$ & $\begin{array}{l}-.044 \\
(.052)\end{array}$ & $\begin{array}{l}-.054 \\
(.073)\end{array}$ & $\begin{array}{l}-.047 \\
(.079)\end{array}$ \\
\hline Economics & $\begin{array}{c}.182 \\
(.252)\end{array}$ & $\begin{array}{l}.148 \\
(300)\end{array}$ & $\begin{array}{c}.491 \\
(.285)\end{array}$ & $\begin{array}{l}-.032 \\
(.478)\end{array}$ \\
\hline Game_theory & $.516^{* *}$ & $.554 *$ & .823 & $.624 *$ \\
\hline
\end{tabular}




\begin{tabular}{cc|c|c|c} 
& $(.174)$ & $(.206)$ & $(.285)$ & $(.310)$ \\
Constant & .636 & .654 & .823 & .742 \\
& $(1.047)$ & $(1.241)$ & $(1.696)$ & $(1.886)$ \\
\hline $\mathbf{N}$ & 3613 & 2895 & 1422 & 1473 \\
Subjects & 168 & 168 & 84 & 84 \\
Phases & All & $2,3,4,5$ & $2,3,4,5$ & $2,3,4,5$ \\
Treatments & Average & Average & Average & Average \\
Log-likelihood & -1869.83 & -1434.43 & -694.35 & -738.95 \\
Wald chi2 & $188.37 * * *$ & $134.65 * * *$ & $55.28 * * *$ & $81.01 * * *$ \\
\hline
\end{tabular}

Note. $* * *, * *, * *$ denote significance at $1 \%, 5 \%$ and $10 \%$,

respectively. Standard deviation on parentheses

Figure 1. Choices distribution - AverageInfo Treatment (a, b) and AverageNoInfo treatment (c, d).

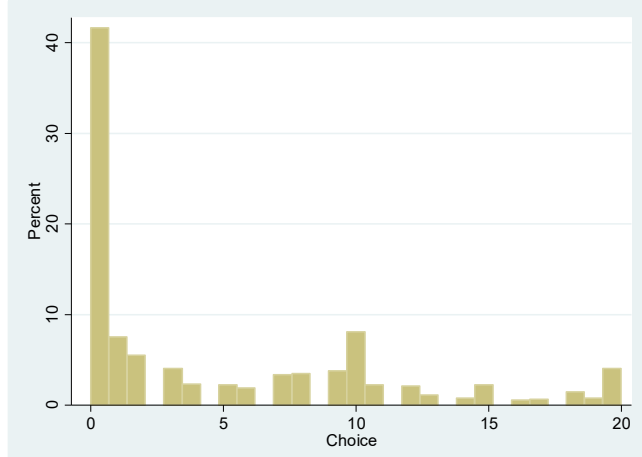

a) Assigned number [1 - 9]

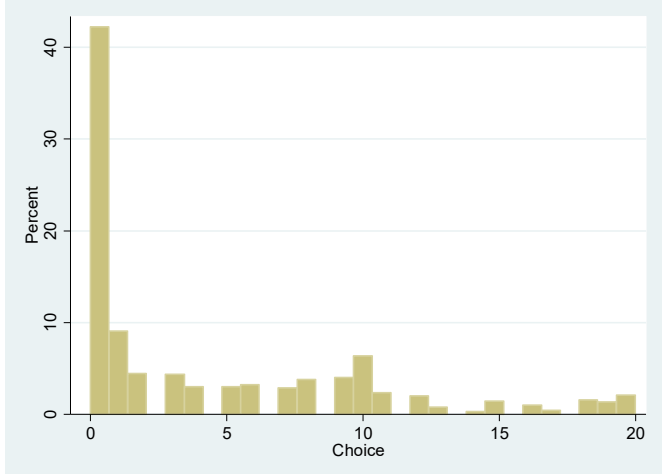

c) Assigned number [1 - 9]

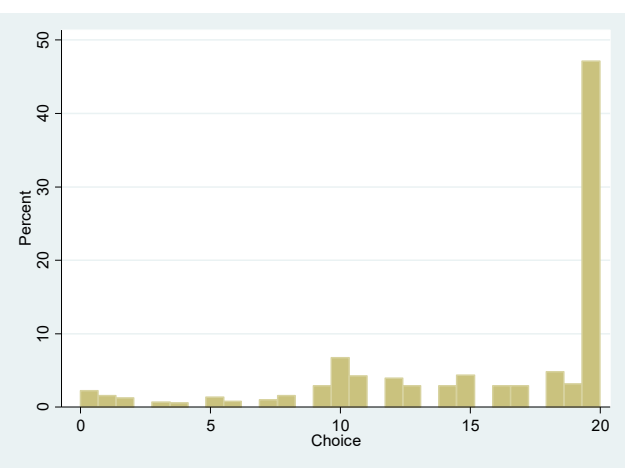

b) Assigned number [11 - 19]

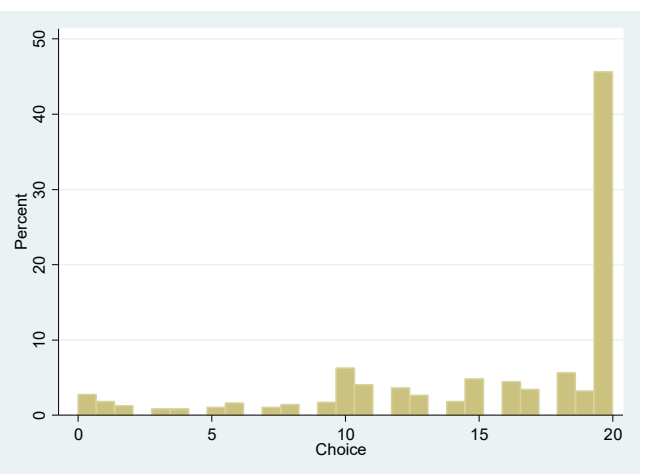

d) Assigned number [11 - 19] 
Figure 2. Proportion of strict strategic voting and strict sincere voting per assigned number AverageInfoTreatment
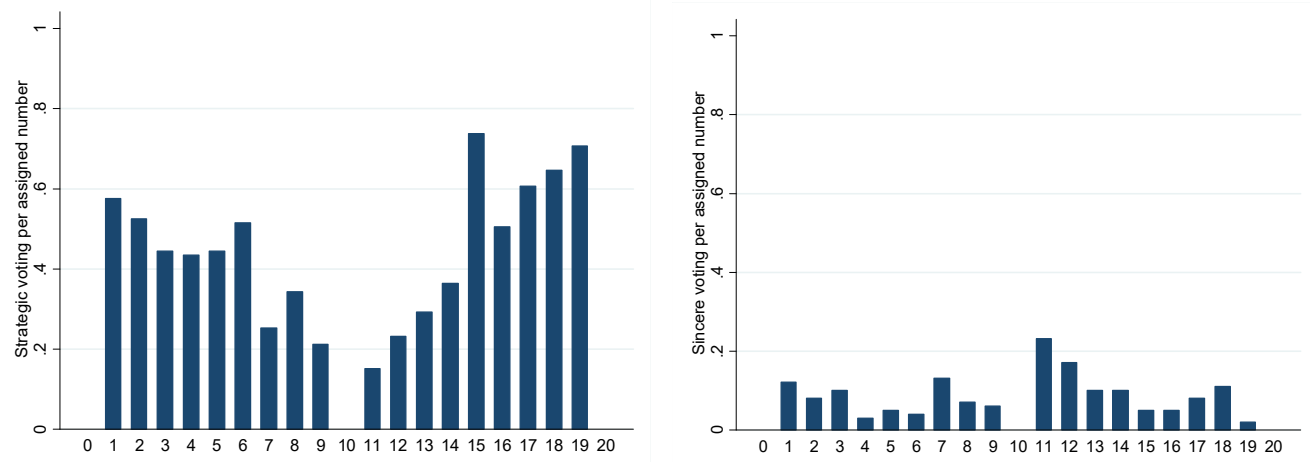

Figure 3. Participants' beliefs, location and choice.

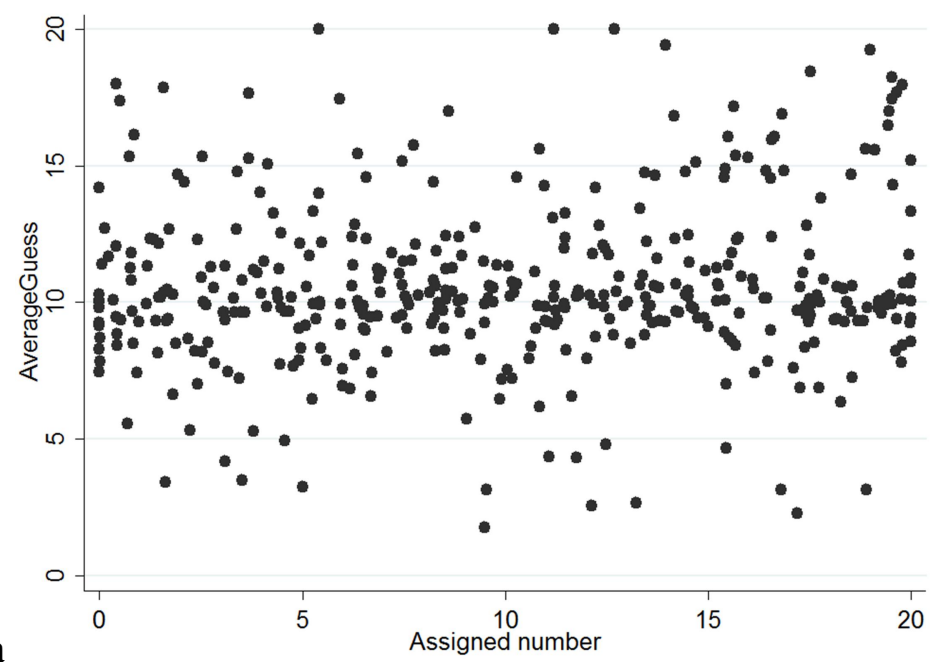

\section{$\mathbf{3 a}$}

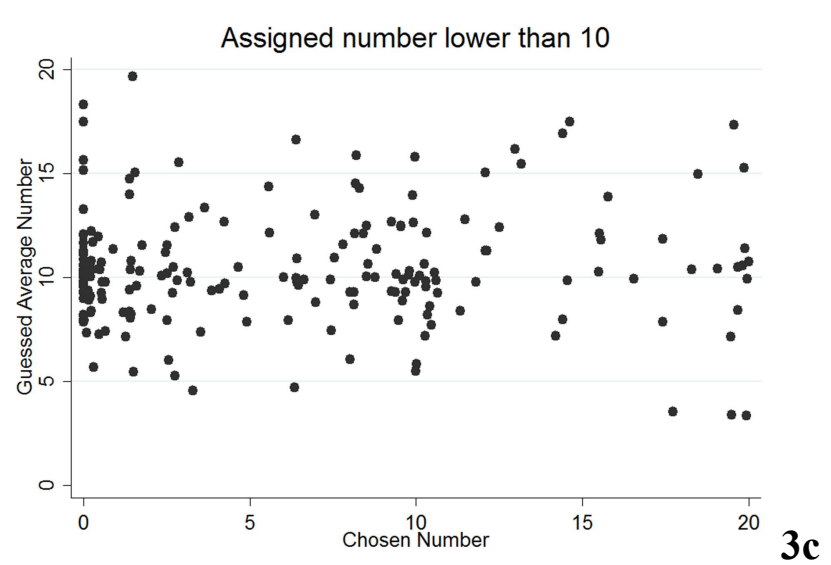

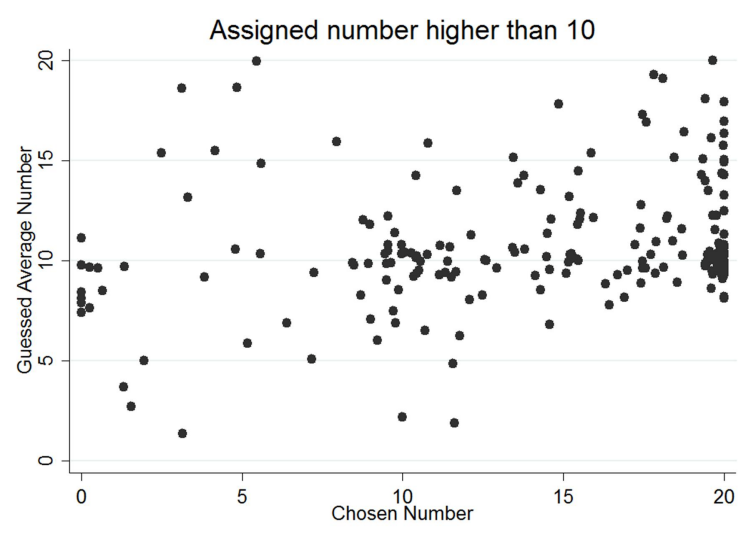


Figure 4. Strategic voting across phases and periods in the AverageInfo and the AverageNoInfo Treatments

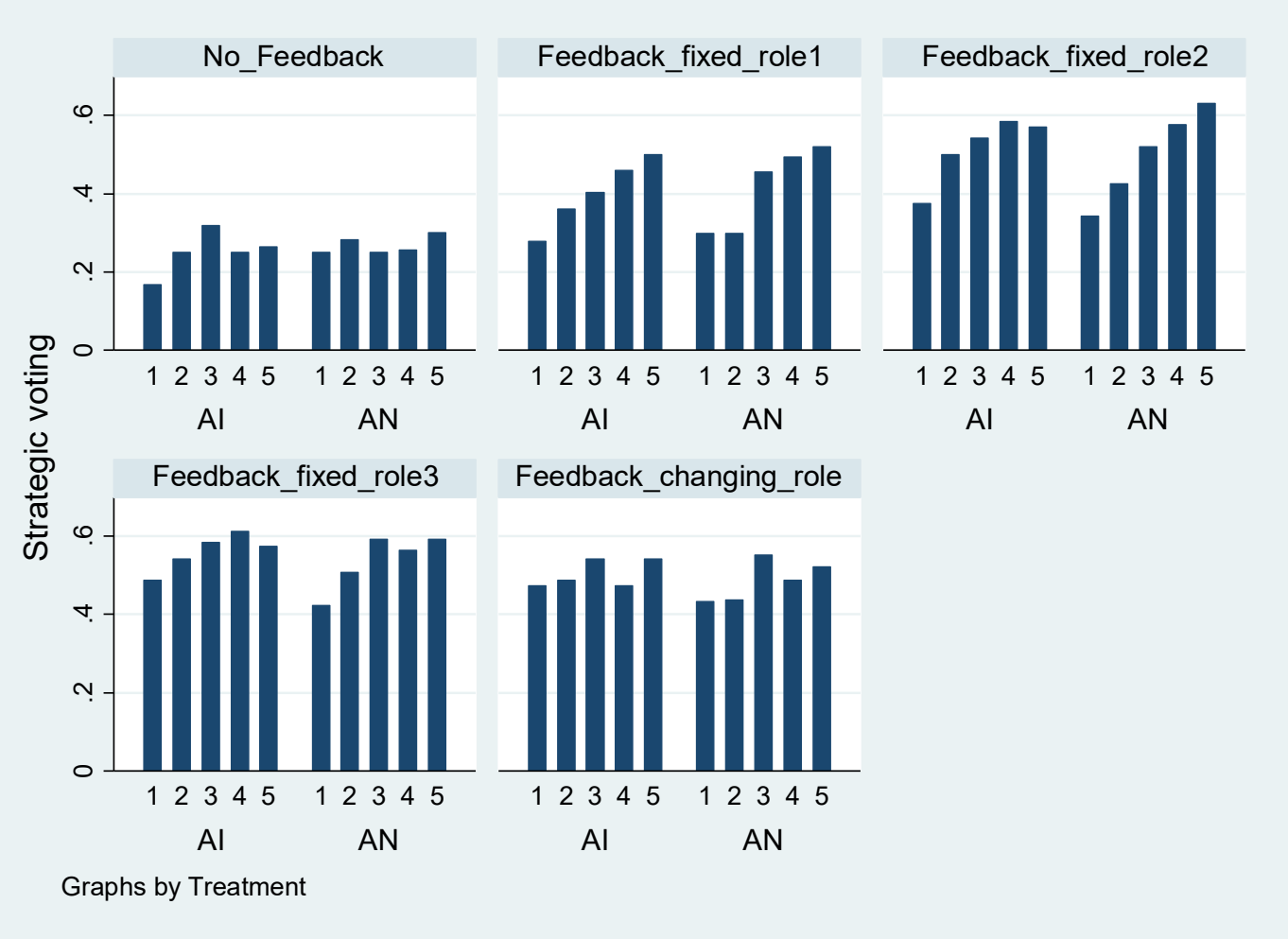

Figure 5. Electoral outcome per round, by treatment.
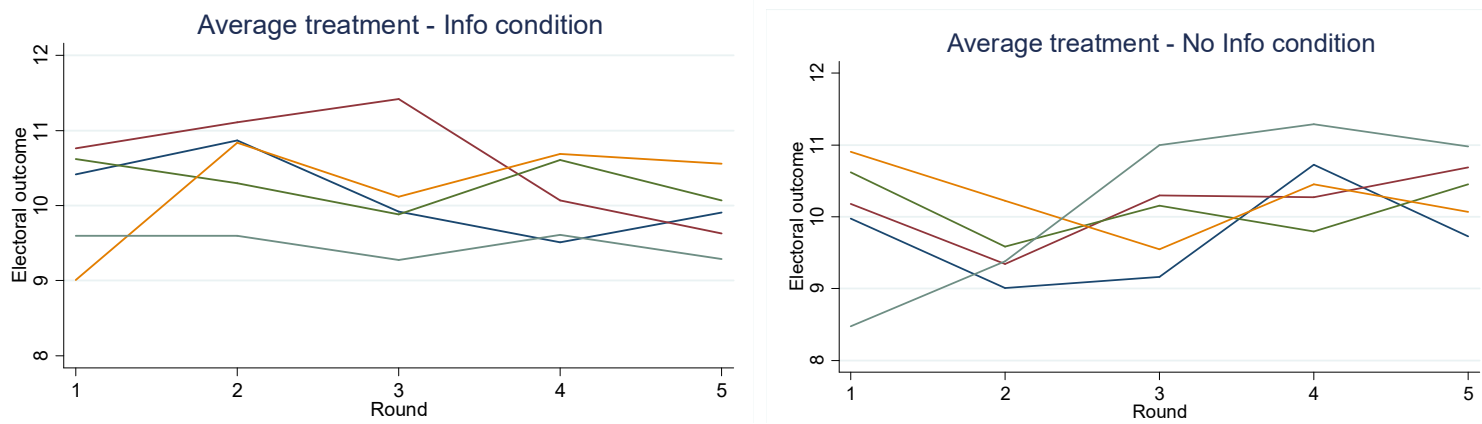
Figure 6. Choices distribution - Median Treatment.

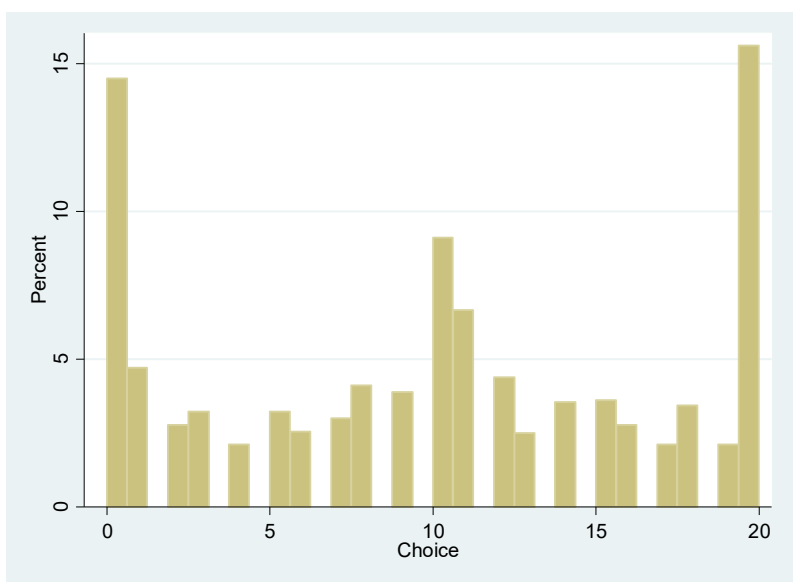

Figure 7 Proportion of Strict Sincere voting per assigned number in the Median treatment.

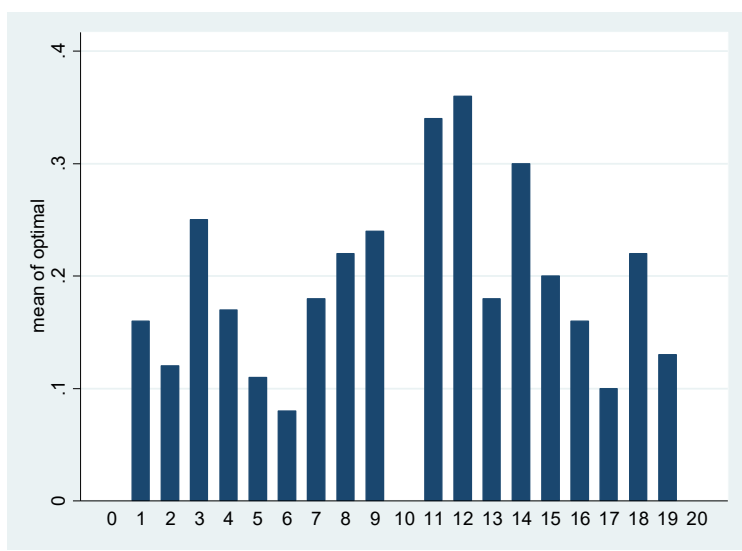

Figure 8. Strategic voting across phases and periods in all treatments

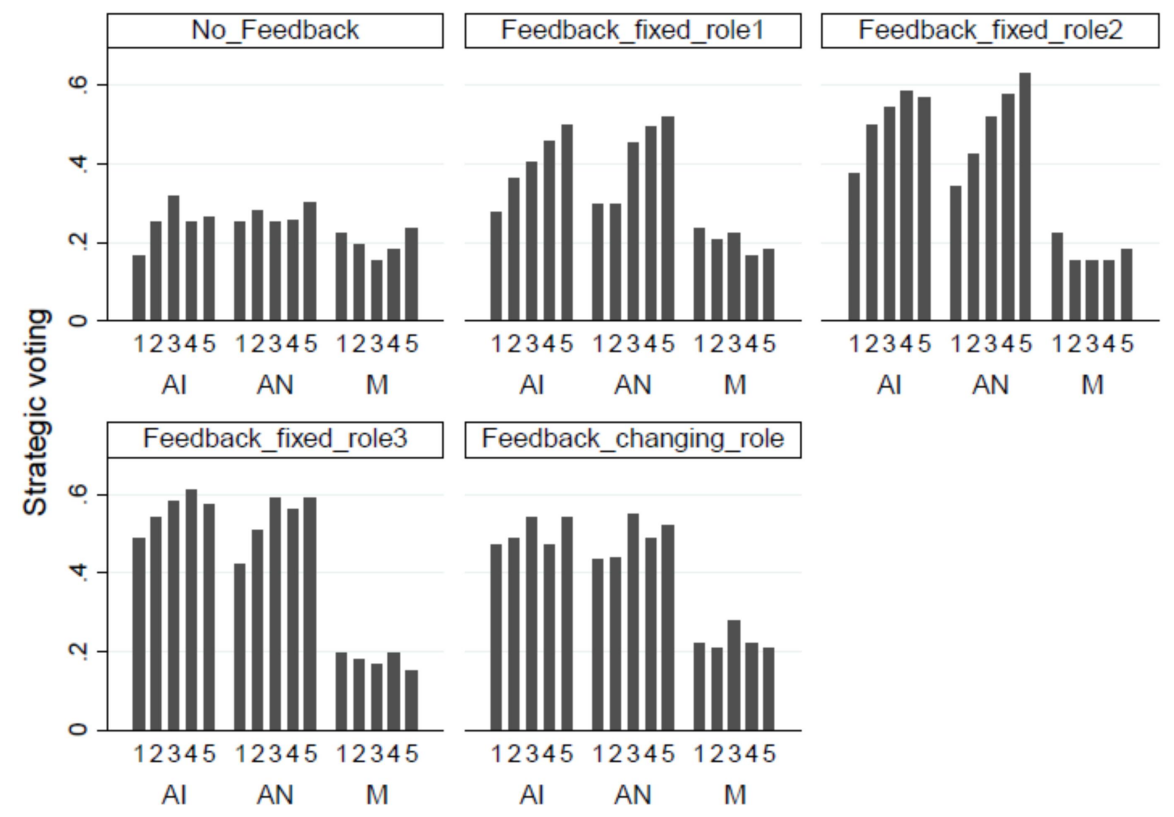


Figure 9. Electoral outcome per round, Median Treatment.

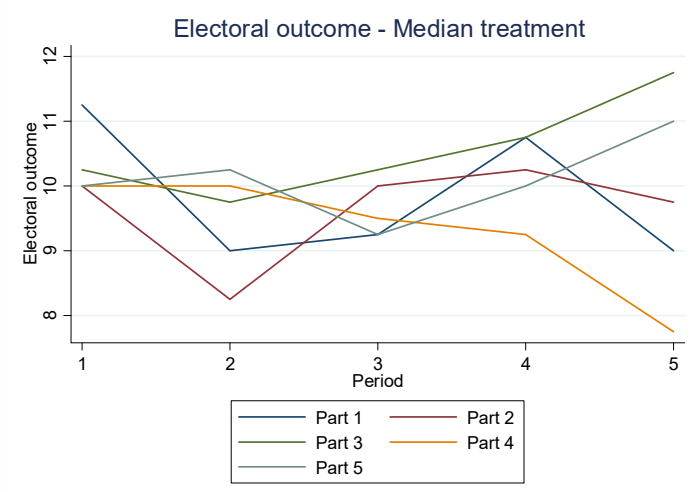




\section{INSTRUCTIONS}

The instructions written in black refer to the INFO AVERAGE treatment, while the instructions written in italics and in green refer specifically to the NO INFO AVERAGE and MEDIAN treatments, respectively.

\section{SCREEN 1}

Thank you for agreeing to participate in this research experiment. During the experiment, we require your complete and undivided attention. Therefore, we ask that you follow the instructions carefully. Turn off your mobile phones. You cannot use mobile phones and you cannot talk with other participants. If you have any questions, then please raise your hand.

\section{SCREEN 2}

The choices you are going to make during the experiment will be completely anonymous. It will be impossible for those analyzing the data to know the participants' identity.

For your participation, you will be paid in cash at the end of the experiment. Different participants may earn different amounts. What you earn depends partly on your decisions, partly on the decisions of others, and partly on chance. Therefore, it is important that you listen carefully and fully understand the instructions before we begin.

You will be paid in private and you are under no obligation to tell others how much you earned. Your earnings during the experiment will be denominated in POINTS. Your EURO earnings will be determined by multiplying your earnings in POINTS by a conversion rate. In this experiment, the conversion rate is 0.15 , meaning that 1 POINT is worth 15 cents.

\section{SCREEN 3}

The experiment consists of five different sessions. Each session will consist of five rounds.

Each round is different from the others; it implies that the choices you will make in each round will not influence your earnings in the next rounds.

At the beginning of each phase, we will read out the corresponding instructions. We will also present some examples to make the instructions clearer.

At the end of the last session, one round from each session will be randomly selected for payment; you will be paid the sum of what you have earned in the two the randomly selected rounds. The points you earn will be converted into Euros and privately given to you in cash. 


\section{SCREEN 4}

In this experiment, there are 21 participants.

In each session, you will be randomly assigned a number between 0 and 20, included. Each number will be randomly assigned to one and only one participant; this implies that it will not be possible for two participants to have the same number.

Numbers are randomly assigned to participants to ensure that that the same number is assigned to more than one participant.

\section{SCREEN 5}

Now, we will be giving you detailed instructions for the first session of the experiment.

The first session consists of five rounds.

At the beginning of each round of this first session, a random number will be randomly assigned to each participant. It is not possible for two participants to have the same number. It is possible that the same number is assigned to more than one participant.

While you will be told your own randomly assigned number, you will not be told if your randomly assigned number is also assigned to other participants or which numbers were assigned to other participants.

Moreover, in each round, a new random number will be assigned to each participant.

After that, you will be asked to choose one number between 0 and 20 included.

How are your earnings determined in every round? It is very important that you understand this, so please listen carefully.

In each round, your earnings would depend on how close your randomly assigned number is with respect to the average/median of all chosen numbers. According to this rule:

\section{Score of each participant $=$}

20 - |average/median of all chosen numbers - participant's randomly assigned number|

You will know your earnings in the randomly extracted round in this first phase of the experiment only at the end of the experiment (at the end of the fifth experimental session).

\section{SCREEN 6}

Given below are a few examples: 
The median is the number that divides all the chosen numbers, sorted in ascending order, into two parts, each composed by the same amount of numbers.

If we consider the numbers " $0,2,2,6,11,17,19,20,20$ ", then the median would be equal to 11 . If we consider the numbers " $0,2,2,5,5,18,19,19,20$ ", then the median would be equal to 5 .

\section{Example 1}

Suppose that the average/median of all chosen number is equal to 10 .

The participants whose assigned number is equal to 2 will get a score of $20-|10-2|=20-8=12$.

The participants whose assigned number is equal to 10 will get a score of $20-|10-10|=20-0=20$.

The participants whose assigned number is equal to 20 will get a score of $20-|10-18|=20-8=12$.

\section{Example 2}

Suppose that the average/median of all chosen number is equal to 3.

The participants whose assigned number is equal to 2 will get a score of $20-|3-2|=20-1=19$.

The participants whose assigned number is equal to 10 will get a score of $20-|3-10|=20-7=13$.

The participants whose assigned number is equal to 20 will get a score of $20-|3-18|=20-15=5$.

\section{Example 3}

Suppose that the average/median of all chosen number is equal to 20 .

The participants whose assigned number is equal to 2 will get a score of $20-|20-2|=20-18=2$.

The participants whose assigned number is equal to 10 will get a score of $20-|20-10|=20-10=10$.

The participants whose assigned number is equal to 20 will get a score of $20-|20-18|=20-2=2$.

\section{SCREEN 7}

We will now start the first round of the first session. In the following screen, you will see your randomly assigned number. After that, you will be asked to choose a number between 0 and 20 included. In order to make a choice, you just have to type your chosen number and click on the "OK” button on your screen.

At the end of the experiment, one round will be randomly selected for payment. Your earnings in the randomly extracted round will be converted into Euros and will be given to you privately in cash at the end of the experiment.

Please begin.

(Play rounds $1-5-$ Session 1) 
In each round, surprisingly, beliefs about the average/median of all chosen numbers are elicited. Particularly, after the participant is informed about his randomly assigned number and has chosen a number between 0 and 20, each participant is asked the expected average/median of all chosen numbers, without considering his own choice. Each participant can flag a "I'm not sure" option when the participant is not confident of own expectation.

\section{SCREEN 8}

Session 1 is now over. We will now begin Session 2. The second, third, and fourth sessions will be slightly different from the first one. Let me summarize those rules before we start. Please listen carefully.

With respect to the first session, in the second, third, and fourth sessions, there will be the following differences:

- The random number that will be randomly assigned to you at the beginning of the first round will also be the same for the subsequent four rounds of the same session;

- In each round, after all participants choose a number between 0 and 20 , you will be informed about the average/median of all chosen numbers and your points in that round;

- Each participant will also see the average/median of all the chosen numbers in the previous rounds of the same session after being informed about the average/median of all the chosen numbers.

\section{SCREEN 9}

We will now start the first round of the second session. In the following screen, you will see your randomly assigned number. Please remember that your randomly assigned number will be the same for all the five rounds of the second session.

At the end of the experiment, one round will be randomly selected for payment. Your earnings in the randomly extracted round of the second session will be added with your earnings in the randomly extracted round of the first session. Subsequently, they will be converted into Euros and will be given to you privately in cash at the end of the experiment.

Please begin.

(Play rounds $1-5-$ Session 2 with feedback)

\section{SCREEN 10}


Session 2 is over. We will now start the first round of the third session. In the following screen, you will see your randomly assigned number. Please remember that your randomly assigned number will be the same for all the five rounds of the third session.

At the end of the experiment, one round will be randomly selected for payment. Your earnings in the randomly extracted round of the third session will be summed up with your earnings in the randomly extracted round of the first and second sessions. Subsequently, they will be converted into Euros and will be given to you privately in cash at the end of the experiment.

Please begin.

(Play rounds $1-5-$ Session 3 with feedback)

\section{SCREEN 11}

Session 3 is over. We will now start the first round of the fourth session. In the following screen, you will see your randomly assigned number. Please remember that your randomly assigned number will be the same for all the five rounds of the fourth session.

At the end of the experiment, one round will be randomly selected for payment. Your earnings in the randomly extracted round of the fourth session will be summed up with your earnings in the randomly extracted round of the first, second, and third sessions. Subsequently, they will be converted into Euros and will be given to you privately in cash at the end of the experiment.

Please begin.

(Play rounds $1-5-$ Session 4 with feedback)

\section{SCREEN 11}

Session 4 is over. We will now start the first round of the fifth session. In the following screen, you will see your randomly assigned number. In this session, unlike the previous ones, you will be assigned a new random number in each round.

Please remember that your randomly assigned number will be typically different in each of the five rounds of this session.

At the end of the experiment, one round will be randomly selected for payment. Your earnings in the randomly extracted round of this last session will be summed up with your earnings in the 
randomly extracted round of the previous sessions. Subsequently, they will be then converted into Euros and will be given to you privately in cash at the end of the experiment.

Please begin.

(Play rounds $1-5-$ Session 5 with feedback)

\section{SCREEN 12}

The experiment is finished. In the next screen, you will see the randomly selected rounds for payment. The sum of the earned points will be your final outcome.

As the last task, we will ask you to answer a rapid questionnaire. Please do not stand up and do not talk with other participants. When everyone has filled the questionnaire, we will give you the instructions for payment.

\section{SCREEN 13}

Here is a list of personality traits that may or may not apply to you. Please write a number next to each statement to indicate the extent to which you agree or disagree with that statement. You should rate the extent to which the pair of traits applies to you, even if one characteristic applies more strongly than the other. 